\title{
RECURSOS SOCIAIS E INSERÇÃO DOS CHARGISTAS NO ESPAÇO DA IMPRENSA ESCRITA EM SERGIPE
}

\section{SOCIAL RESOURCES AND INSERTION OF CARTOONISTS IN SERGIPE'S NEWSPAPERS}

\author{
Wilson José Ferreira de Oliveira* \\ Alex Menezes de Carvalho**
}

\section{Introdução}

Este artigo analisa as condições sociais de entrada e de atuação dos chargistas no jornalismo impresso. Mais especificamente, trata-se de mostrar a importância de inserções prévias no universo jornalístico e de atuações na produção de desenhos artísticos para a obtenção, por parte dos produtores de charges, de recursos passiveis de serem utilizados para a sua inserção nos jornais.

0 material que serviu de base para a construção do artigo consistiu de uma pesquisa desenvolvida sobre um conjunto de chargistas que desenham ou já desenharam para jornais em Sergipe. Entre outras coisas, esta pesquisa demonstrou que o sucesso como produtor de charges para jornais está associado à posse de um conjunto de recursos e competências derivado das esferas jornalística e artística (de desenho artístico, especificamente). 0 presente artigo, porém, está centrado no exame dos critérios que balizam a entrada dos produtores de charges na imprensa. Nesse sentido, os dados apontam que essa inserção é presidida pelo acionamento de redes de relações e pela mobilização de outros recursos adquiridos pelos chargistas em suas inserções na própria esfera jornalística e na das artes visuais. Por

\footnotetext{
* É doutor em antropologia social, professor e pesquisador do Programa de Pós-Graduação em Sociologia e do Programa de Pós-Graduação em Antropologia (UFS, Aracaju/SE), é bolsista produtividade do CNPq e coordenador do Laboratório de Estudos do Poder e da Política (LEPP/UFS). etnografia.politica@gmail.com ** É doutorando em sociologia pelo PPGS (UFS, Aracaju/SE) e pertence ao Laboratório de Estudos do Poder e da Política (LEPP/UFS). max_alex86@ hotmail.com

1. Esta pesquisa foi realizada para a conclusão de uma dissertação de mestrado de título "Jornalismo em forma de desenho: recursos sociais e inserção dos chargistas no espaço do jornalismo impresso em Sergipe" e que foi realizada no programa de Pós-Graduação em Ciências Sociais da UFS em 2013, sob a orientação do Prof. Dr. Wilson José Ferreira de Oliveira. Para a construção deste trabalho foram entrevistados um total de oito chargistas.
} 
isso, ainda que o trabalho esteja centrado na análise do chargismo de jornais, ele possibilita levantar algumas questões relacionadas às credenciais de entrada na imprensa dos ocupantes das demais posições jornalísticas (repórter, fotógrafo, colunista, entre outros). Com relação à coleta e levantamento dos dados para a presente investigação, a principal fonte de informações foram as entrevistas com os chargistas selecionados para os fins da pesquisa. Por sua vez, estas foram gravadas e realizadas entre os meses de fevereiro e setembro de 2012.

A elaboração do esquema investigativo posto em prática para a compreensão do fenômeno descrito acima enfrentou algumas dificuldades. A principal delas foi a escassez de estudos que contribuíssem para pensarmos as dinâmicas de produção de charges para jornais. Isso porque a maioria dos trabalhos sobre essa temática segue na linha das ciências da linguagem e tem como preocupação a análise da charge do ponto de vista discursivo, analisando o poder comunicativo, o alcance e os usos que podem ser feitos desta forma de expressão imagética. Especialmente no que tange à literatura brasileira sobre o tema, os estudos analisam a charge como forma de manifestação de posicionamentos políticos e dos constrangimentos à liberdade de expressão durante a ditadura militar (1964-1985).

Ao tratar da estruturação do espaço do chargismo e dos critérios de inserção nesse espaço, esse trabalho defrontou-se com uma problemática mais ampla que trata dos processos de constituição e/ou profissionalização de atividades ocupacionais. No tratamento dessa problemática, as análises orientadas pela chamada "sociologia das profissões” constituíram um ponto de partida fundamental. Ocorre que as vertentes sociológicas mais profícuas no estudo das profis- sões no século XX - as abordagens funcionalistas e interacionistas - naturalizam os processos de profissionalização, o que pode ser percebido pelo fato de a maior parte dos trabalhos tomarem o título acadêmico como critério formal e essencial de recrutamento nas profissões. No entanto, um dos problemas que não encontrou um tratamento adequado no âmbito de tais abordagens é o que diz respeito à importância de outros recursos que, articulados ao título formal, contribuem para o ingresso em tais atividades. Isso fica claro quando Bourdieu (1989), ao tratar das estratégias de reprodução sociais de cunho educativo, nos demonstra que o rendimento do título escolar pleiteado por um indivíduo depende do capital social (ou mesmo econômico) por ele herdado. Em consonância com isso, alguns trabalhos nacionais sobre espaços diversos (CORADINI, 1996 sobre a medicina; PETRARCA, 2007 sobre o jornalismo; BONELLI, 1999 sobre o espaço do direito) têm demonstrado como o título escolar não é uma garantia exclusiva de acesso ao recrutamento e à seleção no espaço profissional. Pelo contrário, o que esses trabalhos vêm evidenciando é que o valor do título escolar depende da articulação com outros recursos sociais possuídos pelo indivíduo e convertíveis para o espaço profissional pleiteado.

A partir dos anos 1980 e 1990, a sociologia das profissões ganhou um novo foco, na medida em que o processo de profissionalização passou a ser tomado como resultante de estratégias individuais e também coletivas que, por sua vez, estão sujeitas a outras estratégias concorrentes ou complementares para além da definição de um conjunto de saberes próprios, do desenvolvimento de instituições responsáveis pela formação de quadros e da delimitação de um campo de atuação específicos (BOIEGOL; DEZALAY, 1997). 
Dessa forma, o processo contínuo de construção das profissões, ou melhor, de definição de suas bases e de delimitação de suas fronteiras se tornou uma linha de investigação nas ciências sociais. É esse sentido que a presente pesquisa busca seguir, ao constatar que o chargismo não se apresenta como uma atividade juridicamente constituída nos moldes das profissões tradicionais (medicina e direito, especialmente) e, portanto, não podemos "transplantar" para nossa investigação um modelo de análise que trata de profissões oficialmente delimitadas. É somente tomando os chargistas de jornais como uma atividade especifica que podemos perceber o quanto ela constitui um espaço de atuação profissional com critérios e regras próprias e o quanto a entrada neste espaço é regida por um conjunto específico de credenciais.

Autores como Boiegol e Dezalay (1997) e Bourdieu (2007), demonstram como a construção de um espaço profissional é influenciada pela bagagem social dos agentes que lhes dão vida e, por conseguinte, pelos recursos sociais detidos por estes. Nesse sentido, para tratar das modalidades de entrada no chargismo e, consequentemente, das suas credenciais, faz-se indispensável uma análise dos recursos adquiridos pelos chargistas e que podem ser acionados para a inserção no chargismo jornalístico. $\mathrm{Ou}$ seja, defendemos a ideia de que a análise dos condicionantes sociais que conduziram um conjunto diversificado de agentes a desenhar charges para jornais representa uma boa saída para a apreensão das dinâmicas, ou melhor, das particularidades e das lógicas sociais dessa atividade.

Para a análise das condições de acesso dos chargistas ao jornalismo, se fez necessária uma investigação de suas inserções e de como elas atuaram no sentido da aquisição de recursos passíveis de serem convertidos em possibilidades de atuação na imprensa. 0 exame empírico daquilo que importa para a inserção dos produtores de charges nos jornais e de como se dá esse jogo que define suas posições no ambiente de trabalho só foi possível mediante a análise de seus itinerários. Para tanto, a noção de carreira é aqui aceita na forma como Becker (2008) a entende. Segundo este autor, a carreira refere-se a duas dimensões da vida de um indivíduo: em sua dimensão objetiva, a carreira compõe-se de uma série de posições e funções claramente definidas e assumidas por um indivíduo; em sua dimensão subjetiva, ela é composta pelos ajustes das percepções e dos sentidos dados por uma pessoa à sua existência e ao significado das suas características, ações e a tudo que lhe aconteceu ao longo de sua vida. Tendo sido desenvolvido originalmente para estudos sobre grupos profissionais, tal conceito foi forjado para dar conta de compreender mais profundamente a sequência de posições ocupadas por um indivíduo num sistema ocupacional, e isso se efetiva por meio da atenção dada aos fatores que regem essa mobilização posicional ou às "contingências de carreira" (BECKER, 2008, p.35). 0 tratamento dos fatores que agem sobre o posicionamento de um agente, num espaço profissional determinado, torna necessário considerar tudo que, direta ou indiretamente, pode interferir no "sucesso" e "crescimento" nesse universo. Ou seja, tanto as aspirações, as motivações e as percepções individuais quanto os recursos (títulos, experiências profissionais, competências, qualificativos, etc.) mobilizados por um agente devem ser considerados em uma investigação sobre um grupo profissional. 
Em outras palavras, a análise de carreiras se apresentou como uma prática fundamental para a construção deste trabalho. Esse procedimento metodológico permitiu a apreensão das bases sociais que sustentam a presença dos chargistas na imprensa, bem como a compreensão da importância que os recursos oriundos dessas bases assumem no tocante à inserção e ao posicionamento deles no jornalismo. Essas bases dizem respeito às diferentes esferas sociais nas quais os agentes se vinculam em alguma medida no momento atual de suas trajetórias, mas também àquelas esferas com as quais mantiveram vínculos em outros momentos de suas vidas e que podem ser reatualizadas (CORADINI, 2001).

A ênfase sobre as bases sociais de sustentação dos chargistas na imprensa tem, aqui, uma intenção clara: é demonstrativa da nossa preocupação com relação às regras e aos princípios e critérios de recrutamento/ seleção de chargistas para jornais. Muitos são os critérios que, direta ou indiretamente, agem sobre a seleção de integrantes nas diversas atividades. Assim sendo, torna-se necessário tomar os recursos acionados pelos chargistas no decorrer de suas carreiras de forma articulada e não de maneira isolada. Quanto a isso Bourdieu (2007) demonstra que as chances de proveito numa determinada esfera dependem dos recursos disponibilizados pelos agentes, o que não significa que qualquer recurso, independentemente da origem, pode se constituir num trunfo em qualquer espaço. Em consonância a isso, consideramos que a en- trada e o posicionamento de um chargista no jornalismo têm como base um conjunto diversificado de qualificativos e competências sociais por eles possuídos e que podem ser acionados para o universo da imprensa. Em outros termos, isso justifica uma análise do conjunto das inserções/vinculações dos chargistas, pois somente assim se faz possível verificar a importância de cada inserção para a obtenção dos recursos que os qualificaram para a atuação na imprensa.

\section{0 "Despertar" para o chargismo no es- paço do jornalismo}

As discussões que fazem parte desse trabalho dizem respeito às características sociais do conjunto dos chargistas considerados, aos seus trajetos profissionais e ao jogo realizado por eles com os recursos detidos. Nesse sentido, faz-se necessário trazer à luz alguns esclarecimentos acerca de como se constitui este grupo de chargistas, quais são as suas divisões e qual a composição social de tais artistas do traço. 0 ponto de partida é esclarecer as suas características em termos de idade, sexo e distribuição de funções.

0 número de produtores de charges para jornais em Sergipe não é muito grande. Até o ano de 2012, o jornalismo sergipano conta com cinco chargistas distribuídos entre todos os impressos noticiosos do estado ${ }^{2}$. Esse dado foi levantado durante a própria pesquisa visto que, a exemplo da maioria dos estados brasileiros, Sergipe não conta com nenhuma entidade de classe representativa

2. Vale ressaltar, entretanto, que o jornal Super Popular, um impresso semanal que começou a circular em Aracaju a partir de janeiro de 2011, contou com algumas colaborações esparsas ("Mamg” confeccionou algumas charges no segundo semestre de 2011, Clécio Barroso publicou algumas gravuras chargísticas em 2012 e Pablo Carranza assinando às vezes como Lúcio Gregório o fez entre finais de 2012 e fevereiro de 2013), mas que não foram muito além de uma dezena de gravuras. 
para essa categoria. 0 número relativamente baixo de chargistas atuantes representa, também, um dado interessante, pois não se trata aqui de uma pesquisa com base estatística, mas de uma análise de um grupo com características particulares. Por isso, outros três chargistas inativos foram incluídos nesta investigação para um melhor entendimento das características do grupo.

Um primeiro aspecto que chama a atenção no universo investigado é a grande homogeneidade dos entrevistados quanto ao gênero e à origem familiar. Todos os oito casos são representados por indivíduos do sexo masculino, revelando um aspecto muito comum ao chargismo em geral, na medida em que quase não se encontram chargistas do sexo feminino. Semelhante homogeneidade se encontra também com relação à origem social, na medida em que todos vêm de famílias de origem social baixa ou média baixa.

No entanto, ao se analisar os demais indicadores, o conjunto apresenta traços relativamente heterogêneos. Ao analisar os percursos sócio-profissionais dos oito chargistas sergipanos considerados, observamos que a grande maioria está na faixa etária dos 40 anos. Ou seja, 1/8 tem entre 20 e 30 anos e os outros 7/8 têm mais de 40 anos, sendo que destes $3 / 7$ têm entre 40 e 50 anos, 3/7 têm entre 50 e 60 anos e 1/7 tem entre 60 e 70 anos. Em que pese essa predominância da faixa etária, cabe observar que todos eles começaram a produzir charges para jornais na juventude, entre os últimos anos de escola e os 30 anos de idade, sendo que sete dos oito atuaram como chargistas em meados da década de 1980, no período da redemocratização do Brasil, que se consistiu num momento de grande profusão do desenho chargístico nos impressos. Esse último dado é importante porque durante o período da ditadura militar brasileira (1964-1985) o jornalismo alternativo (ou imprensa nanica) ${ }^{3}$ se confundia com a articulação das esquerdas, sendo que a maior parte dos impressos alternativos eram ligados a partidos políticos contrários à ditadura (KUCINSKI, 2003). Muito politizada, essa imprensa tinha o sensacionalismo e o humor político como máximas, de modo que não faltaria espaço para os desenhos de humor e as charges se tornarem a cara da crítica política desse período. Nesse contexto, o desenho chargístico se expandiria, também, para a "grande imprensa” (SODRÉ, 1999) criando um terreno profícuo para a atuação de chargistas no jornalismo em todo o país.

Outro dado que deve ser examinado juntamente com esse, diz respeito ao momento do trajeto profissional em que é iniciada a carreira de chargista. Dos oito artistas do traço contatados sete só se iniciaram no chargismo e só começaram a desenhar

3. Chama-se jornalismo alternativo a prática jornalística realizada por veículos noticiosos que não estão diretamente vinculados aos grupos políticos e/ou econômicos dominantes num dado período. Isso ocorreu, por exemplo, durante a ditadura militar no Brasil de 1964 a 1985, pois nesse momento floresceu uma modalidade de imprensa diferente da praticada regularmente e que se filiava às esquerdas, com políticas contrárias à ditadura. Essa modalidade de jornalismo também ficaria conhecida como imprensa nanica. Tal nomeação adveio do fato de a maioria dos impressos dessa linha se utilizarem do formato tabloide, aproximadamente $33 \times 28 \mathrm{~cm}$, ou seja, dimensões menores que a dos jornais tradicionais. 
charges para jornal após experiências profissionais anteriores no próprio espaço jornalístico. Destes, cinco começaram nos impressos como ilustradores, um como publicitário e um como diagramador. Esse dado é duplamente importante porque é demonstrativo de que o chargismo é mesmo muito ligado à prática jornalística e aponta para o fato de que o trabalho de produção de charges para jornais é uma atividade ligada a agentes que se inserem no espaço da imprensa em posições periféricas. Esta última afırmação é também validada quando nos debruçamos sob as titulações destes desenhistas, apenas dois deles têm formação acadêmica na área jornalística, sendo que um deles depois de formado deixou de produzir charges para se dedicar a outras funções dentro das redações.

Seguindo esta última assertiva acerca das funções atualmente desempenhadas pelos chargistas contatados, quatro deles desenvolvem atuações no universo artístico (pintura e desenho artístico mais precisamente), todos eles desempenham outras atividades remuneradas para além do chargismo e apenas cinco deles desenham atualmente para jornais, sendo que um desenha para dois impressos simultaneamente. Destes, dois são contratados por empresas jornalísticas somente para confeccionar charges, dois têm participação como sócio da empresa para a qual desenha e, por isso, não é remunerado por sua atuação chargística, e um desempenha outra função no impresso além de chargista, sendo a primeira a principal. Outra informação importante com relação às atividades profissionais dos chargistas considerados é que apenas um deles tem/ teve o chargismo como atividade principal: trata-se de um produtor de charges para quem o chargismo de jornais representou sua atividade principal e que compõe o con- junto dos três chargistas hoje inativos, fato que ocorreu entre 2001 e 2011. Com relação aos rendimentos, seis chargistas são ou já foram remunerados por seu trabalho com charges. Desses, três têm/tiveram esses rendimentos representando em torno de $40 \%$ do seu orçamento, dois têm/tiveram como complemento de renda e um tem/teve esses rendimentos como fonte de renda principal. Com relação aos rendimentos totais dos chargistas considerados, somando todas as suas atividades remuneradas, temos quatro com renda até cinco salários mínimos atuais (até $\mathrm{R} \$ 3.390,00$ ), dois com renda de cinco

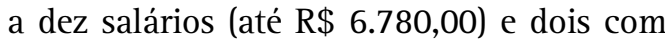
rendimentos maiores que dez salários (maior que $\mathrm{R} \$ 6.780,00)$.

Como todos esses dados indicam, o conjunto analisado é relativamente heterogêneo em quase todos os indicadores lançados. Eles permitem vislumbrar que os atuais postos de chargistas de jornais são ocupados por desenhistas de charges que comungam de percursos socioprofissionais muito próximos, como origem social baixa, despertar para o chargismo posterior à entrada no jornalismo e atividade chargística representando ocupação e fonte de renda secundárias.

Todo esse esforço acerca das características socioprofissionais do grupo estudado nos traz informações valiosas a respeito do “mundo dos chargistas de jornais". Porém, para que esses dados tenham valor para o presente trabalho, eles precisam estar associados a outros indicadores, tais como espaços profissionais percorridos, contatos realizados e a relação mantida por todos esses indicadores nos diferentes contextos. Nesse sentido, os dados acima analisados são expressão de uma dimensão importante da emergência e da consolidação do chargismo no Brasil e sua estreita relação com o espaço do jornalismo. 


\section{Chargismo: uma forma de atuação jor- nalística}

Pensar em chargismo é pensar em uma forma de atividade ligada ao espaço da imprensa e à prática jornalística. Em primeiro lugar, ele é herdeiro do jornalismo ilustrado surgido na Inglaterra e na França entre a segunda metade do século XVIII e inícios do XIX. Em segundo lugar, o desenho chargístico guarda em si características estruturais (de construção e de realização) que são próprias aos constructos jornalísticos, sobretudo no que diz respeito aos textos opinativos: uma charge pode funcionar num jornal tal como uma matéria ou mesmo um editorial ${ }^{4}$. Ou seja, tomada por esse viés a atuação do chargista nos jornais se aproxima à do jornalista. Segundo Melo (2003), a imprensa é o "verdadeiro" lugar da charge, pois é nesse espaço que ela adquire todo seu sentido.

A chegada do desenho chargístico ao Brasil data dos anos 1800, mas somente no século seguinte é que ele passou a ser praticado em larga escala em nossos jornais. Disseminando-se pelo país na virada do século XIX para o XX, o chargismo brasileiro adquiriu muitas de suas principais características durante o regime militar de 1964 a 1985 na chamada imprensa alternativa ou nanica. Altamente politizada e sensacionalista, essa imprensa tinha como característica o humor político que era expresso, entre outros recursos, pelas charges.
Com relação à inserção dos chargistas no jornalismo, a produção de charges para jornais esteve ligada até a década de 1980 a uma "categoria profissional" de vital importância para os impressos noticiosos de até então: os desenhistas manuais ou ilustradores 5 . Diante da inexistência ou baixa difusão de recursos técnicos de confecção de gravuras ou desenhos, a elaboração de todo arsenal gráfico (gráficos, logotipos, layouts, anúncios, charges e outros desenhos, etc.) dos jornais até esse momento era um trabalho realizado à mão. Ou seja, até esse período os trabalhos de confecção de charges e de outros tipos de ilustrações para as folhas se confundiam e era isso que garantia a presença de desenhistas de charges na imprensa. Porém, com a assimilação de recursos informacionais de produção gráfica pela mídia impressa, os ilustradores perderam muito do seu espaço e uma reordenação no setor jornalístico de produção iconográfica ocorreu.

Tal reordenação contribuiu para a delimitação e especialização das atividades ligadas à confecção de gravuras para jornais. Com a assimilação dos recursos da informática gráfica pela imprensa quase todo o trabalho de elaboração de recursos gráficos passou a ser dominada pelo uso de técnicas e procedimentos informatizados, somente a elaboração de desenhos humorísticos permaneceu nas mãos dos artistas do traço. 0 espaço jornalístico de criação ilus-

4. 0 editorial é o texto de jornal ou de outra mídia que passa para os leitores a opinião oficial do meio de comunicação que o veicula, da sua direção ou mesmo da equipe de redação. Este texto é veiculado sempre nas primeiras páginas internas de um impresso e não se atém a critérios como imparcialidade ou objetividade.

5. Os produtores manuais de gravuras ou ilustradores representavam para o jornalismo impresso de até finais dos anos 1980 a possibilidade de veiculação de desenhos e gravuras, pois até esse momento poucas tecnologias de produção gráfica tinham sido desenvolvidas e difundidas na imprensa. Desenhistas polivalentes, esses "profissionais" realizavam uma vasta gama de produções gráficas (anúncios comerciais, mapas, gravuras ilustrativas para as matérias, desenhos humorísticos) e, dentre elas, charges. 
trativa passou a dividir-se em dois: aquele dedicado à confecção de gravuras para a apresentação do jornal (logotipos, desenhos publicitários, ilustrações para as matérias, gráficos, tabelas), espaço que ficou sob os cuidados dos infografistas ou designers gráficos; e aquele destinado à elaboração de charges e de outros desenhos crítico-humorísticos que, por sua vez, restou a cargo dos desenhistas manuais: chargistas e cartunistas $^{6}$. Diante desse contexto, houve também um processo de diferenciação entre os chargistas e os cartunistas. Como resultado disso tivemos a constituição de um espaço de atuação próprio para os produtores de charges para jornais, sendo que a sua inserção na imprensa passou a ser balizada por um conjunto de credenciais específico.

Apresentando-se como uma atuação quase sempre secundária na vida dos que a ela se dedicam, o chargismo de jornais não é uma atividade que conte com grande espaço de atuação: em média, há espaço para uma dezena de chargistas atuarem na imprensa de uma capital brasileira com três ou quatro milhões de habitantes. Além do mais, inexistem critérios formais para o recrutamento desses desenhistas para os impressos. Do mesmo modo como ocorre em alguma medida nas seleções das demais atividades e/ou profıssões, a inserção no mercado de trabalho para os chargistas também é pautada pela necessidade de utilização de um conjunto diverso de experiências e/ou recursos sociais. A inserção num impresso na posição de produtor de charges é garantida àqueles que, para além do domínio da arte de desenhar, podem lançar mão de recursos sociais passíveis de serem utilizados para esta inserção. Mas, quais seriam esses recursos e como eles agem nas colocações dos chargistas na imprensa?

Para responder a essa questão, discorreremos sobre as modalidades de ingresso no chargismo de jornais e sobre os fatores que balizam esse ingresso. Mais especificamente, trata-se de mostrar o jogo realizado entre os recursos advindos de inserções intra e extrajornalísticas para a atuação e o reconhecimento enquanto chargista de jornais. Nesse sentido, foi observado que a inserção em diferentes espaços e a capacidade em mobilizar os recursos oriundos dessas inserções apresentou-se como uma possibilidade de desenvolver uma carreira como chargista dentro de jornais. Dentre os espaços e os recursos mobilizados, estão aqueles relacionados ao desenho e à pintura artísticos e, especialmente, ao interior das próprias redações jornalísticas. As análises dos trajetos profissionais dos chargistas serão direcionadas, portanto, ao tratamento das relações existentes entre a posse de recursos oriundos dos universos artístico e jornalístico com o exercício do chargismo de jornais. Mais especificamente, busca-se compreender os mecanismos e as formas de reconversões de recursos sociais para a defınição do chargista profissional e seu sucesso no espaço da imprensa. A principal tarefa a partir de agora é analisar as modalidades de ocupação da posição de chargista de jornal e os seus respectivos princípios de legitimação.

6. A exemplo dos chargistas, os cartunistas também são produtores de desenhos de humor. Porém, diferentemente dos primeiros, não possuem ou não se utilizam de competências jornalísticas em seu trabalho. Ou seja, os cartunistas produzem desenhos de humor com temáticas variadas diferentes da política como tiras e cartuns. 


\subsection{Inserção dos chargistas nos jornais: combinações de recursos e conversões}

Historicamente, o espaço de atuação jornalístico tem como característica uma maior flexibilidade com relação às suas credenciais de entrada e atuação profissional. No Brasil, mesmo depois da regulamentação da profissão jornalística e do consequente estabelecimento da exigência de título acadêmico específico como critério objetivo para a atuação na imprensa, a atuação neste universo ainda é plenamente possibilitada a não detentores desta titulação (estudantes, pesquisadores, profissionais liberais, religiosos, artistas, entre outros). Segundo o Decreto-lei no 83.284, de 13 de março de 1979, lei que regulamenta o exercício profissional jornalístico no Brasil desde então, as funções de ilustrador, repórter fotográfico, repórter cinematográfico, diagramador e algumas condições especiais ${ }^{7}$, também outras funções dispensam formação na área jornalística. Tais fatores, juntamente com o fato de em muitos estados brasileiros, os primeiros cursos superiores para a área em questão somente terem sido fundados nas décadas de 1980 e 1990, sem mencionar as disputas jurídicas em torno da exigência de tal titulação ao longo dos últimos anos, aumentaram ainda mais as oportunidades de atuação na imprensa para os "não jornalistas".

Diante disso, fica-nos uma questão: o que faz pertinente e reconhecida a atuação dos colaboradores nos jornais? Ou melhor, já que estamos tratando de chargistas, o que faz legítima e diferenciada a presença e a atividade desses desenhistas num impresso? A resposta está nos recursos acumulados pelos chargistas e que podem ser convertidos para o espaço jornalístico. Segundo Bourdieu (2007), a "construção" de um espaço profissional não se dá de forma unívoca e nem independente de outros espaços, mas envolto em disputas internas em torno dos mecanismos de legitimação. Esse processo, ou melhor, essas disputas por pertencimento e reconhecimento não se dão somente no âmbito profissional, mas acabam comprometendo os recursos que os agentes acumularam ao longo de toda a sua vida e que resultam de sua origem social, formação escolar e inserção em outras esferas de atividade (BOIEGOL; DEZALAY, 1997; BOURDIEU, 1984 e 2007; BOLTANSKI, 1982).

Assim, e admitindo que os recursos sociais são "os poderes" que balizam as probabilidades de sucesso num espaço dado (BOURDIEU, 2007), entendemos que no processo de entrada e estabelecimento na esfera da imprensa os recursos arrecadados pelos chargistas em suas inserções diversas são acionados para definir a sua posição enquanto integrantes desse universo. Com relação à natureza desses recursos, o que alguns trabalhos acerca da profissão jornalística (RIEFFEL, 1984 e PETRARCA, 2007) têm demonstrado é que, entre outros, os recursos advindos do investimento profissional nas redações e as redes de relações

7. De acordo com Art. 50 deste decreto-lei, o Ministério do Trabalho concede, desde que satisfeitas as exigências constantes deste mesmo decreto, registro especial para o desenvolvimento de atividades dentro dos jornais a não graduados na área jornalística. Os casos previstos são: a - colaborador, ou seja, aquele que mesmo sem relação de emprego, produz trabalhos de cunho técnico, científico ou cultural veiculado com créditos para o autor; $\mathrm{b}$ - funcionário público titular de cargo cujas atribuições legais ajustam-se às dos jornalistas; c - provisionado. 
desempenham forte papel na ocupação de cargos e posições na imprensa. Em se tratando do chargismo de jornais, a análise das carreiras consideradas também segue nessa linha e destaca os recursos advindos do investimento na própria esfera jornalística e as redes de relações sociais como preditores do sucesso de atuações chargísticas em jornais, isso sem falar na importância dos recursos originários do universo artístico nesse sentido.

\subsubsection{As passagens pelas redações e a aqui- sição de recursos para a inserção na imprensa}

0 papel desempenhado pela socialização profissional dos chargistas na imprensa, no tocante à arrecadação de recursos acionáveis para atuações nesta mesma esfera, é explícito. Trata-se de qualificativos que os chargistas adquirem em inserções no meio jornalístico e que não podem ser apreendidos de outro modo, tais como reconhecimento por atuações chargísticas na imprensa, habilidades em lidar com os limites de liberdade de expressão impostos aos chargistas pelos gestores de impressos, capacidade de definir o que é digno de ser tratado numa charge destinada a jornais e como isto deve ser tratado, entre outros. Ou seja, estamos tratando de qualidades que só podem ser assimiladas na prática jornalística e que podem servir para recolocações e/ou remanejamentos dentro do próprio jornalismo. E isso fica evidente até para os próprios chargistas, conforme relato a seguir do chargista João ${ }^{8}$.
0 chargista ele vive assim como se ele tivesse embaixo de chuva (...) então é isso, é como se fosse uma chuva ... tudo que a gente pensar ele entra aqui e já descortina, e principalmente quando a gente adquire uma prática de quarenta anos de jornalismo.

Pergunta: Nessa produção sua de charges, nesse tempo todo nos jornais, você já sofreu algum tipo de censura ou constrangimento à sua produção?

Censura eu passo sempre né, sempre (...) tem jornalista aqui em Sergipe que tem medo de político, tem medo de todo mundo aí às vezes eles censuram alguma charge minha, mas é besteira porque depois eu... eu guardo (...) depois eu publico em outro jornal, mas não adiantou nada. (...) Porque o jornalista aqui em Sergipe ele ainda é um pouco assim comandado pelo dono do jornal (...) 'ó porque isso aqui não pode... porque eu sou amigo de fulano, fulano é meu amigo' (Entrevista com João).

Conforme podemos ver neste depoimento, João possui competências indispensáveis ao chargismo de jornais e reconhece o papel desempenhado pela sua experiência na imprensa para o desenvolvimento das mesmas. Para deixar essa afırmação mais clara, vale ressaltar que o desenhista em questão tem 62 anos de idade, ilustra jornais em Sergipe desde meados da década de 1970 e já produziu charges para a maioria dos impressos sergipanos dos últimos quarenta anos e até para a televisão e, para isso, teve que se adequar às condições de

8. Visando preservar a identidade dos chargistas entrevistados, os mesmos são identificados ao longo do texto por nomes fictícios escolhidos pelo autor. 
atuação chargística ao longo de toda a sua carreira, que já dura quase quatro décadas. Ou seja, teve que se adaptar aos limites de atuação para desenhistas de gravuras satírico-políticas no universo jornalístico, teve que adquirir habilidades fundamentais para o desenvolvimento da atividade de chargista de jornais e tudo isso lhe serviu e lhe serve como um recurso, ou melhor, como um dos pilares de sua extensa carreira chargística na imprensa.

Outra forma de percebermos a importância da experiência profissional no jornalismo como promotora de recursos acionáveis para reinserções neste mesmo universo pode ser a observação das condições históricas de desenvolvimento do setor de produção de recursos imagéticos para impressos. Tomando a realidade da imprensa local, a qual passou a contar com um setor de criação gráfica a partir da década de 1970, nossos primeiros "profissionais do desenho" eram, de maneira geral, gravadores contratados apenas com a finalidade de desenhar ou agentes já inseridos nos jornais com outras funções e que acumularam esta nova atividade. Inicialmente, esses desenhistas eram ilustradores polivalentes, ou seja, eles eram responsáveis por todos os tipos de trabalhos relacionados à confecção de recursos imagéticos para as folhas (charges, anúncios comerciais, desenhos ilustrativos para as matérias, vinhetas, etc.), porém, essa realidade se alteraria drasticamente entre fınais dos anos 1980 e inícios dos 1990. A disseminação das tecnologias de computação gráfica no jornalismo nesse período acabou por restringir a atuação dos desenhistas manuais nos impressos, e quase toda a parte referente à criação imagética restou pautada pelo uso de tal tecnologia, ou melhor, ficou sob os cuidados dos seus operadores: os infografistas. Diante disso, boa parte do espaço dos desenhistas manuais na imprensa foi retirado. Esse contexto teria outro desdobramento, qual seja, balizou a especialização do trabalho de produção imagética para jornais dando origem a modalidades específicas de desenhistas, dentre elas, a do chargista.

Nesse primeiro momento de profissionalização do chargismo jornalístico, o trabalho de criação de charges ficou sob a responsabilidade de desenhistas que já vinham atuando nos impressos como ilustradores polivalentes. Graças aos recursos jornalísticos e/ou gráfıco-jornalísticos adquiridos pela atuação na imprensa, muitos ilustradores de jornal passaram a ser reconhecidos enquanto chargistas e, com isso, puderam continuar atuando onde já trabalhavam ou migraram para outros impressos ocupando a posição de chargista. Nesse quesito, mais uma vez, o percurso profissional de João vai nos servir de elemento clarificador. Iniciando sua carreia no Jornal da Cidade em 1975, e tempos depois passando a desenhar para diversos jornais de Sergipe, esse desenhista produziu durante anos diversas modalidades de gravuras para impressos, sobretudo publicitárias. Porém, com a informatização dos setores de produção imagética dos jornais e com a consequente redução das possibilidades de atuação dos ilustradores nessas empresas, esse desenhista se especializou na confecção de charges. Foi nesse momento que os recursos adquiridos por ele em sua passagem pelo jornalismo fizeram a diferença, já que foi baseado neles que ele se diferenciou de tantos outros desenhistas de jornais e se transformou num dos chargistas mais afamados do jornalismo sergipano.

Diante disso, pode-se perceber que atuações na imprensa são, pelas características da atividade e do espaço de produção de 
charges para jornais, fornecedoras de recursos fundamentais para o sucesso de um chargista profissional. Muitas competências chargísticas só podem ser desenvolvidas através de inserções no jornalismo e essas habilidades funcionam como fatores de distinção no momento da entrada nesta atividade. Experiências nas redações dos jornais podem ser convertidas numa espécie de "capital de reconhecimento" na "tribo jornalística”, numa demonstração de que referenciais de pensamento para trabalhar são compartilhados e isso acaba pesando na hora de um chargista ser aceito num impresso.

\subsubsection{As atuações gráfico-artísticas como credenciais para o chargismo jornalístico}

Dentre as facetas do chargismo, uma das mais evidentes é a de que ele representa uma modalidade de arte. Nesse sentido, uma das entradas para a análise das condições de seu exercício é pensar seus praticantes em relação ao universo artístico. Assim procedendo, foi verificado que alguns integrantes do corpo dos chargistas considerado também possuem outras inserções no universo artístico para além do chargismo, especificamente nas artes gráficas (pintura, grafite, etc.). 0 fato de um chargista também praticar outra modalidade de arte, especialmente quando se trata de artes gráficas, traz a possibilidade de um reconhecimento interno ao jornalismo da posse de competências/qualificativos passiveis de serem convertidos em recursos para a entrada na imprensa na posição de chargista. E isso pode ser notado nos excertos a seguir (o primeiro é uma fala da Diretora Geral do Jornal Povão, um im- presso da cidade de Aracaju e o segundo é um trecho do texto de apresentação de um chargista por parte do Portal Lagartense - versão digital do Folha de Lagarto, um jornal da cidade sergipana de Lagarto e, portanto, expressão oficial desta empresa de mídia).

Pergunta: 0 Jornal Povão conta com charges?

Olhe, aqui em Sergipe nós só temos três chargistas que são Edidélson, Álvaro e Alcosa [estes três nomes integram o corpo dos oito chargistas considerados nesta pesquisa] que são verdadeiros artistas... quem não gostaria de contar com artistas do porte de Edidélson, Álvaro e... e Alcosa?, mas no momento não temos condições (Diretora Geral do Jornal Pavão).

Semanalmente estaremos publicando charges e desenhos do grande artista lagartense Rogério Bonifácio. Os desenhos publicados em sua maioria serão ilustrações que abordam o cotidiano da grande cidade Lagarto e região. Rogério também está escalado para o Jornal Impresso. Seja bem-vindo à equipe, Rogério!?.

Como podemos ver nesses excertos, o fato de um produtor de charges ser reconhecido como artista representa um diferencial, um qualificativo que importa aos gestores dos jornais no ato da sua contratação. Vale ressaltar, entretanto, que os recursos que um produtor de charges pode tirar de suas atuações na imprensa podem se confundir com os recursos jornalísticos que estes mesmos desenhistas podem adquirir em experiências de naturezas diversas no jornalismo. Para

9. Disponível em < http://www.lagartense.com.br>, publicado em 01 de janeiro de 2013. Acesso em 03 mar. 2013. 
ser mais específıco, não se está tratando aqui dos recursos que um desenhista pode adquirir em atuações na imprensa como forma de reconhecimento, por parte da própria imprensa, de sua posição enquanto artista, mas sim de como atuações artísticas extrajornalísticas possibilitam a aquisição de recursos convertíveis em credenciais para colocações no universo jornalístico.

Isso não significa dizer, contudo, que trabalhos gráficos (desenhos humorísticos e outras produções imagéticas) publicados em jornais que tenham seu valor artístico reconhecido por organizações não jornalísticas não se configurem como "fontes" de recursos artísticos para chargistas. Esse é o caso de três dos desenhistas de charges contatados para esta pesquisa: Antônio, chargista de 59 anos de idade e larga experiência na imprensa escrita aracajuana; José, chargista e artista plástico de 43 anos de idade que atua na imprensa sergipana desde a década de 1980; e Pedro, chargista e também artista plástico de 60 anos de idade, mas que atualmente não produz mais charges para jornais. Antônio ficou com o $2^{\circ}$ lugar no 33 Salão Internacional de Humor de Piracicaba-SP de 2006; José ficou com o $1^{\circ}$ lugar em três edições não sequenciais do Prêmio Banco do Brasil de Jornalismo ${ }^{10}$ na categoria charge; e Pedro desenhou a charge agraciada com o primeiro lugar no $1^{\circ}$ Salão Sergipano de Humor. Outra atuação que também contribui para a aquisição do status de artista por parte de um chargista é a ilustração de livros. Em se tratando desse requisito, todos os oito produtores de charges entrevistados preenchem o perfil, já que todos eles já ilustraram ao menos um livro, conforme se pode ver em: As peripécias do esporte sergipano, do jornalista Joel Batalha; Liberdade de Imprensa, do jornalista Claudio Nunes; A lenda do Caju, do professor Antonio Wanderley; Dá licença doutor e As aparências enganam, de Ailton Cardoso; A Cerca de Vidro, do poeta Assuero Cardoso; e Tupinanquim: humor gráfico, de José Augusto Araújo e Marcos Cardoso.

Ainda com relação às fontes de reconhecimento das habilidades artísticas dos chargistas, a análise empírica demonstrou que elas vão além das atuações na imprensa e das ilustrações de livros. Pois, dos chargistas contatados três desenvolvem atuações significativas em artes gráficas: Marcos, Pedro e José. Marcos, um chargista de 29 anos que também trabalha com grafite sobre papel, já conta em seu currículo com um amplo acervo de obras que lhe rendem grande prestígio artístico em sua cidade natal - Lagarto, interior de Sergipe - conforme podemos observar no trecho a seguir:

Neste sábado, 09, a partir das 20h30, acontece, na Praça da Igreja, a Mostra Plástica (...). Nela estarão expostas publicamente obras do artista lagartense [cujo nome foi suprimido]. As obras do também chargista inspiram um mundo imaginário extremamente interessante: a realidade material se mistura com um surrealismo impressionista elaborado com técnicas de grafite que surpreendem aos olhos. Ele certamente é um dos mais talentosos artistas de Sergipe. E o melhor: teremos uma oportunidade única de prestigiar e valorizar o melhor da arte e da cultura lagartense $^{11}$.

10. Concurso de produções do jornalismo sergipano realizado anualmente por iniciativa do Bando do Brasil e do Sindicato dos Jornalistas de Sergipe (SINDIJOR-SE).

11. Disponivel em < http://www.lagartense.com.br>. Publicado a 08 de abril de 2011. Acesso em 22 mar. 2013 
Já com relação aos chargistas Pedro e José, seus nomes constam de compêndios de biografias de artistas plásticos (pintores e/ou escultores) que desenvolvem ou desenvolveram atuações artístico-visuais em Sergipe como, por exemplo, o dicionário Dois Séculos de Artes Visuais em Sergipe ${ }^{12}$ e o portal EDUCAR-SE ${ }^{13}$ :

[Pedro]. Nasceu em Rio de Janeiro-RJ em 31 de outubro de 1953. Trabalha com charges e caricaturas desde os dezoito anos. (...) Além de chargista e caricaturista é também pintor e escultor, realizando diversas exposições coletivas e individuais. (AZEVEDO, CHOU e SANTOS, 2008, p.75).

[Pedro]. "Sergipano" nascido no Rio de Janeiro, veio para Aracaju ainda menino. Designer Gráfico, desenhista, pintor, caricaturista e escultor (...) Além das artes plásticas, confecciona também bonecos gigantes. Seu hobby atual é fazer esculturas em areia pelas praias de Sergipe. (http://www.educar-se. com/v3/index.php/personalidades/506-belem, acessado em 23 de março de 2013). [José]. Nasceu em Aracaju-SE em 19 de novembro de 1966. Em 1988 expôs pela primeira vez na Galeria Florival Santos - Cultart/Universidade Federal de Sergipe-SE na sua individual "Figuras Surrealistas". (...) Muralista experimenta várias técnicas e suportes, a exemplo dos painéis do Balneário do SESC/Atalaia, do Terminal Fernando Sávio, da Codise, do Centro de Convenções CIC, do Deso. Em 1990, ganhou o Prêmio Horácio Hora no II Salão de Artes Plásticas do Festival de Arte de São Cristóvão - FASC/São Cristóvão-SE. (AZEVEDO, CHOU e SANTOS, 2008, p. 26-27).

Como visto acima, os chargistas tratados possuem ampla atuação na esfera artística, pintam, ilustram, fazem decoração artística, sendo que um deles chega até a confeccionar máscaras e bonecos gigantes e a realizar esculturas em areia. Um desses dois casos merece ser mais bem explorado aqui: trata-se do itinerário artístico de José. Expondo suas telas desde os 16 anos de idade, este artista plástico já participou e foi premiado em mostras artísticas realizadas em diferentes cidades brasileiras, tais como Salvador (1992), Brasília (?), Santos (1991) e também no exterior (Providence, Rhode Island, Estados Unidos, 1992). Em Sergipe, além de várias exposições recebeu o prêmio Horácio Hora de Artes Plásticas $^{14}$ em quatro ocasiões e venceu o concurso A Cara da Cidade ${ }^{15}$ em 1995. Ao longo dos anos 1990, produziu painéis-murais para o Balneário do SESC (Serviço Social do Comércio) situado à Orla de Atalaia em Aracaju, para a DESO (Companhia de Saneamento Básico de Sergipe), para o DETRAN/SE (Departamento Nacional de Transito, seção Sergipe) e para alguns viadutos da cidade de Araca$\mathrm{ju}$, isso sem falar do projeto Caju na Rua ${ }^{16}$

12. Este catálogo é resultado de um projeto realizado pelo governo do estado de Sergipe em parceria com a Fundação Nacional de Artes (FUNARTE), o Ministério da Cultura e a Sociedade Semear.

13. Trata-se de um sítio na internet criado, alimentado e mantido pelo governo do estado de Sergipe e que traz um apanhado histórico das personalidades artísticas, políticas e intelectuais sergipanas.

14. Concurso realizado pela galeria sergipana de arte Horácio Hora.

15. Concurso e mostra artística realizada pela prefeitura de Aracaju por ocasião do aniversário de 140 anos da capital sergipana em 1995.

16. 0 projeto que se dá pela implantação de estátuas de cajus enormes pintadas por artistas locais em diferentes pontos da cidade, a ideia da prefeitura (organizadora do projeto) é transformar Aracaju num museu a céu aberto. 
de 2011. Como chargista de jornais, iniciou em finais dos anos 1980, e ao tomarmos seu itinerário chargístico, teremos uma noção de como sua posição no chargismo jornalístico cresceu em importância juntamente com o desenvolvimento de sua carreira artística. Vejamos o relato a seguir:

(...) na Gazeta [no jornal Gazeta de Sergipe] eu comecei fazer muito tempo... até sem receber, depois comecei receber como tituleiro e muito tempo, muitos anos depois é que teve uma brecha aqui..., lá no sindicato e regularizou, eu tava pronto, fazendo charge, mas ganhando como tituleiro, salário mínimo, né. Aí eles... depois de muitos anos viu, foi que chegou uma senhora chamada Valéria (...) no jornal aí se sensibilizou com minha situação, gostou de mim também aí acabou que ela mandou regularizar minha profissão. Aí eu passei a ganhar como jornalista ilustrador (Entrevista com José).

As atividades de José no Gazeta de Sergipe se deram entre 1988 e 2004 e, conforme relato, em seus primeiros tempos neste impresso suas atuações com charges não eram recompensadas financeiramente. Essa situação só mudaria anos depois quando, mesmo sem fazer títulos, ele foi contratado como tituleiro ${ }^{17}$ e passou a ser remunerado como tal (um salário mínimo). Contudo, sua atuação chargística nesse jornal só passou a ser melhor remunerada "depois de muitos anos”, mais precisamente em finais da década de 1990, quando ele teve sua situação profissional regularizada. Ou seja, quando adquiriu o registro de jornalista por tempo de atuação na imprensa ${ }^{18}$, foi registrado na empresa como jornalista (mas para exercer a função de chargista) e passou a receber o referente a esta profissão. 0 que chama mais a atenção neste caso é que o reconhecimento em forma de um progressivo aumento de remuneração vivenciado pelo chargista em questão no Gazeta de Sergipe se deu, conforme dados apresentados neste tópico, justamente no mesmo período em que este agente experimentou um reconhecimento elevado de sua atuação artística. Não se está com isso querendo dizer que os rendimentos econômicos são a única manifestação de reconhecimento que uma empresa jornalística pode oferecer a um chargista, mas sim que eles se convertem em um bom indicador disso. 0 fato é que à medida que o trabalho artístico de José foi ganhando projeção a sua posição no Gazeta de Sergipe foi mudando: pouco a pouco ele foi deixando de ser um colaborador (aqui entendido como aquele que não é remunerado por serviços prestados), passou a receber uma baixa remuneração e depois se tornou um chargista bem pago.

17. Ocupação relacionada à impressão dos títulos nos jornais. Esta atividade tinha lugar no Brasil até os anos 1990, quando as tecnologias usuais de impressão exigiam o trabalho manual de reprodução dos títulos das matérias jornalísticas, letra por letra, nos suportes de papel em que os jornais eram montados para a posterior reprodução.

18. Trata-se do jornalista que, mesmo não possuindo uma titulação acadêmica na área de jornalismo, adquire o registro de jornalista junto ao Ministério do Trabalho. Tal prática se tornou comum nas décadas de 1970 e 1980 devido a criação de uma lei (Decreto-Lei no 972, de 17 de outubro de 1969, alterado pelo Decreto no 83.284, de 13 de março de 1979) estabelecendo a necessidade de um título acadêmico específico para a atuação na imprensa. Essa mesma lei, entretanto, deixava brechas para que aqueles que já atuavam nos jornais antes da promulgação dessa lei solicitassem o registro de jornalista por tempo de serviço. 
Enfım, os dados mobilizados neste tópico nos levam a entender como atuações artísticas por parte de um chargista podem interferir no reconhecimento, por parte das empresas jornalísticas e do próprio espaço jornalístico, da sua atuação chargística nos jornais. Mais especificamente, foi demonstrado que em se tratando dos produtores de charges outras atuações artísticas podem fornecer recursos convertíveis para inserções no espaço da mídia como, por exemplo, consagração por parte da imprensa do reconhecimento artístico experimentado pelos trabalhos extrajornalísticos dos chargistas.

\subsubsection{A importância das redes de relações}

Conforme demonstrado por Rieffel (1984) e Petrarca (2007), as redes ou o “capital de relações" são fundamentais na atividade jornalística para o acesso privilegiado a determinados espaços, para o reconhecimento dentro do próprio jornalismo e para maiores possibilidades de ascensão profissional. Além do mais, quanto maior é a rede de um profissional da imprensa e quanto maior é a sua capacidade em mobilizá-la, mais chances ele tem de ocupar posições mais altas numa empresa jornalística e/ou no espaço da imprensa. Nesse sentido, sendo o chargismo de jornais uma "profıssão jornalística" as premissas citadas acima sobre o poder das redes de relações para o jornalismo também lhe são válidas em alguma medida, e é justamente sobre este tema que discorreremos neste tópico.

Uma "rede social", conforme demonstrada por Pierre Mercklé (2004), constituise por um conjunto de unidades sociais de tamanhos variáveis (indivíduos, grupos de indivíduos informais, associações de classe, entre outros) e das relações que, direta ou indiretamente, estas unidades man- têm umas com as outras: desde relações mais impessoais (transações bancárias, por exemplo) até interações mais próximas (interações verbais, por exemplo). Ou seja, o que nos deve ficar claro é que as redes de relações sociais se convertem em um "espaço” de interação entre indivíduos e de estabelecimento de novas interações com outros individuos ou grupos.

Dentre as muitas possibilidades de mobilização das redes que os produtores de charges podem realizar no espaço jornalístico, uma se destacou na análise do grupo estudado: aquela que age no sentido da entrada destes desenhistas nos jornais. Possuir e manter muitos vínculos é muito importante para quem atua na imprensa, pois como demonstra Rieffel (1984) o jornalista competente não é, a priori, o mais escolarizado, mas aquele que melhor souber investir em seus vínculos, crescer e se beneficiar por meio deles e frente a eles. Para os produtores de charges, manter "boas relações" funciona muito bem como um fator diferenciador entre os bons chargistas (e que devem desenhar para jornais) e os produtores de charges "menos qualificados” que não encontram espaço no jornalismo. Porém, diferentemente do caso dos jornalistas em que o esforço em constituir um caderno de endereços (ou em ampliar suas fontes de informação) se converte em uma competência profissional fundamental, a situação dos chargistas é um pouco diferente. 0 importante para o chargista não é estabelecer contatos nas diversas esferas ou ter fontes de informação privilegiada, isso é assim porque sua principal função num impresso não é buscar informações ou "produzir notícias", mas opinar a respeito delas. Assim sendo, o que interessa ao produtor de charges é a constituição de vínculos com integrantes 
do círculo da imprensa que possam funcionar como um recurso para a sua entrada no espaço jornalístico e não o estabelecimento de redes como competência profissional.

Conforme já salientado neste texto, o espaço para a atuação de desenhistas de charges na imprensa é reduzido (oito ou dez chargistas atuam no jornalismo de uma grande cidade brasileira), nesse sentido apenas os chargistas mais bem dotados de recursos convertíveis para o jornalismo é que são admitidos. Além das competências jornalísticas e em desenho e dos recursos acumulados na própria imprensa e no universo das artes visuais, os chargistas necessitam constituir elos entre eles próprios e os impressos que possibilitem tornar visiveis seus qualificativos por parte do jornalismo. Pois somente assim é que os produtores de charges podem transformar suas competências e suas experiências em credenciais para a inserção em jornais e revistas. Nesse sentido, que contatos melhores os chargistas poderiam manter do que os estabelecidos com integrantes do círculo da imprensa? Conforme podemos ver nos relatos a seguir, cultivar relações no jornalismo garante aos produtores de charges maiores possibilidades de atuação nos impressos.

No Correio do Povo eu comecei quando teve a intervenção [intervenção estadual que destituiu o prefeito de Aracaju Jackson Barreto em 1988]. Quando teve a... a intervenção aí rompeu, teve um... um grupo com Almeida Lima, Bosco Mendonça que eu trabalhava com ele, que eu trabalhava na SMTT [Secretaria Municipal de Transporte e Trânsito de Aracaju] na época que ele era diretor-superintendente (...). Então essa turma fez um, um, um jornalzinho né [o Correio do Povo], pra combater (...) pra defender a, a... ideolo- gia deles, o grupo né. Então, Bosco Mendonça viu que eu fazia uns desenhos (...) uns desenhos verdes lá do, do mural "catraca felina” (...) um jornal mesmo caseiro nosso [dos funcionários da SMTT à época], um mural mesmo. Aí Bosco viu e mandou eu ir lá pra conversar com Luis Adelmo [um dos responsáveis pelo Correio do Povo] (...) Fiz algumas charges, mas nunca tive problema (...) Aí dona Conceição que trabalhava comigo conversou com Naílson [um jornalista do Gazeta de Sergipe]: 'leve [o chargista em questão] pra Gazeta que não tem chargista lá' (...) aí quando cheguei lá falei com Braynner [editor do jornal à época] aí eu comecei (Entrevista com José).

Tinha um panfleto que a gente fazia aqui [bairro Getúlio Vargas, Aracaju] para denunciar a corrupção que envolvia a polícia (...) eu desenhava as situações, quadrinhos... e distribuía. Na hora de distribuir a gente levava a partido político que naquela época todos [os funcionários dos partidos políticos] tinham uma pontinha dentro de um sindicato (...) acho que é José Araújo o nome dele (...) ele era do movimento sindical [na verdade ele foi presidente do Sindicato dos Jornalistas de Sergipe e Editor Chefe do jornal Correio de Sergipe] (...) ele me fez o convite pra trabalhar no Correio de Sergipe (Entrevista com Paulo, chargista e músico de 43 anos que desenhou charges para o Correio de Sergipe durante a década de 2000).

Como podemos perceber através desses relatos, é muito comum para os chargistas se inserirem em impressos por meio de "indicações" ou "convites”. Contudo, esta não é uma característica específica do chargismo de jornais e é comum, na verdade quase uma regra, também para os outros segmentos da atividade jornalística. Para ser mais 
específico, assim como outros profissionais da imprensa os produtores de charges se inserem e se posicionam no jornalismo auxiliados pelos usos que eles podem fazer das redes de relações tecidas com integrantes do círculo da imprensa.

Ainda com relação à importância das redes como credenciais para o chargismo jornalístico, ela fica ainda mais clara quando atentamos para os itinerários jornalísticos de alguns dos desenhistas contatados. Um desses casos exemplares é o de José que, conforme relato acima, entrou nos jornais Correio do Povo e Gazeta de Sergipe por meio de relações estabelecidas com integrantes do universo da imprensa, já que foi também através desses contatos que ele passou a desenhar charges para outros três impressos. Tomando seu trajeto no jornalismo, este chargista atuou no Gazeta de Sergipe de finais da década de 1980 até 2004 (ano da falência deste impresso), período em que estreitou laços com os promotores de sua entrada no jornal (Naílson Socorro e Diógenes Brayner, jornalistas do Gazeta de Sergipe) e ampliou sua rede de vínculos no jornalismo sergipano. Com o fim da gazeta, este artista do traço passou a desenhar para outros dois impressos: Gazeta New e Jornal do Dia. Sua entrada no primeiro impresso não foi cercada de grandes dificuldades, já que ele foi fundado por ex-colegas seus dos tempos da Gazeta de Sergipe que logo o convidaram para uma nova parceria. Com relação ao Jornal do Dia, impresso para o qual desenha desde 2006, sua entrada se deu através de Gilvan Manoel, um jornalista que trabalhou com o chargista em questão na gazeta e que, ao assumir a editoria geral do Jornal do Dia, convidou-o para integrar a equipe na posição de chargista.

Outro itinerário chargístico que também contribui para um melhor entendimento do papel das redes de relações, no tocante à entrada e à migração de chargistas no jornalismo, é o de João. Ao procurar a diretoria do Jornal da Cidade em 1975 e apresentar-lhe alguns trabalhos em desenho, esse desenhista foi contratado para integrar o setor de produção de ilustrações do impresso e ficou responsável pela confecção de charges de outras gravuras, especialmente publicitárias. Sendo o impresso em questão adquirido, ainda nos anos 1970, por uma tradicional família sergipana com larga inserção na política, na indústria e no ramo das comunicações locais (além do Jornal da Cidade, a esta família pertencem a Rádio Atalaia e as emissoras de televisão TV Sergipe e TV Atalaia), o chargista tratado pôde diversificar seus vínculos e expandir seu raio de atuação com charges na imprensa.

Eu comecei a fazer charges animadas na televisão por intermédio de... de Carlos Mota (...) e ele era um dos editores aqui do Jornal da Cidade e disse "vamo fazer uma charge animada pra a TV Atalaia? Vamo mexer com esse povo? Você tem como fazer isso?' E eu disse 'vou fazer' (...) e aí pronto, aí eu fiz um tempo na TV Atalaia e a TV Sergipe aí me chamou. Na época eu acho que o editor era... Luis Antônio Barreto, só sei que eles me chamaram e eu fui pra a TV Sergipe (Entrevista com João).

Conforme relato, através das suas vinculações com agentes bem situados no espaço jornalístico sergipano esse chargista atuou em outros suportes midiáticos da família Franco. Porém, sendo um dos precursores do chargismo em Sergipe, esse desenhista conseguiu transpor os limites de atuação num grupo familiar e, graças às suas ligações com integrantes do universo jornalístico local, produziu charges para quase 
todos os jornais sergipanos de seu tempo: Jornal da Manhã (atual Correio de Sergipe), Cinform, Jornal de Sergipe, Gazeta de Sergipe, jornais alternativos (a maioria das décadas de 1980 e 1990), entre outros.

Enfim, pelos dados apresentados e discutidos nesta seção, fica claro que as redes de relações dos chargistas desempenham papel importante no desenvolvimento das suas carreiras no jornalismo. Apresentando-se especialmente sob a forma de um "trunfo" ou um algo a mais, as redes de relações podem se converter em um recurso utilizável por parte dos produtores de charges para inserções na imprensa. Mais precisamente, o que queremos deixar claro é que determinados vínculos podem ser acionados como um fator de diferenciação ou como um qualificativo eficaz para a entrada de um chargista num impresso. Enfim, atuando em alguma medida nas diversas atividades e/ou profissões, os vínculos ou as redes sociais se apresentam como um recurso social de extrema valia para os chargistas de jornais, sobretudo no tocante ao processo de diferenciação e inserção destes desenhistas nos impressos.

\section{Considerações finais}

Focando em itinerários diferentes, este artigo atentou para as credenciais de entrada no chargismo jornalístico. Por se tratar de uma atividade com critérios de entrada e exercício diferentes dos de profissões juridicamente constituídas, ou melhor, por não possuir uma definição formal das suas credenciais de entrada e atuação e nem instância ${ }^{19}$ institucionalmente direcionadas ao seu fornecimento, nosso foco recaiu sobre os qualificativos detidos pelos chargistas passíveis de serem acionados para a inserção no jornalismo. Ou seja, tratar dos recursos/qualificativos possuídos pelos produtores de charges que desenham para impressos foi a forma encontrada para entender como estes profissionais do desenho conseguem se inserir na imprensa e desenvolver uma carreira nesse espaço. Assim procedendo, foi percebido que passagens anteriores pelas redações e o desenvolvimento de atividades gráfico-artísticas (desenho e pintura artísticos, especificamente) por parte dos chargistas, juntamente com as redes de relações estabelecidas nessas inserções, se apresentaram como grandes fornecedoras dos recursos balizadores da inserção desses desenhistas num jornal.

0 chargismo é uma atividade que tem como meio de realização o desenho artístico, sendo assim, certos recursos ligados à atuação dos chargistas com artes visuais podem servir para a inserção destes no espaço jornalístico. Conforme visto, competências e/ou reconhecimento social relacionados à confecção de gravuras artísticas ou a atuações com trabalhos iconográficos (pinturas artísticas e ilustração de livros, especificamente) se apresentam como valiosas credenciais para a entrada dos produtores de charges nos impressos. Nesse sentido, um dos direcionamentos do exame dos itinerários "profissionais" dos chargistas entrevistados foi a compreensão de como esses qualificativos atuam nas colocações e nos posicionamentos desses desenhistas no

19. Ou seja, instituições dedicadas à formação de quadros ou espaços em que, mesmo sem um direcionamento ao ensino do ofício,,a passagem represente o reconhecimento da arrecadação de competências chargísticas. 
espaço da imprensa. Como resultado, ficou demonstrado que a detenção, por parte dos chargistas, desses recursos/competências ligados a experiências artístico-visuais é consagrada pelo jornalismo. Ou seja, representa um atributo de diferenciação que importa aos gestores de empreendimentos jornalísticos no tocante à contratação de um produtor de charges.

Em contrapartida, se o chargismo jornalístico tem como forma de apresentação o desenho, sua realização requer o domínio de certas competências indispensáveis à atuação na imprensa. 0 que a análise dos percursos profissionais dos chargistas contatados também deixou claro é que determinadas habilidades próprias ao espaço jornalístico são fundamentais para a atuação como chargista de jornais. Com relação à apreensão dessas habilidades, eles têm na vivência interna ao próprio jornalismo sua principal forma de assimilação. Ou seja, isso transforma experiências anteriores, em posições diversas e muito diferentes da de chargista, no universo da mídia em fontes de recursos importantes para a inserção e para o desenvolvimento de carreiras na imprensa por parte dos chargistas. Com relação à natureza desses recursos, eles podem assumir tanto a forma de alguns saberes fundamentais à atuação no jornalismo, quanto se manifestar sob alguma modalidade de reconhecimento interno ao espaço da imprensa do pertencimento ao grupo. 0 conhecimento das regras gerais de produção e de atuação no jornalismo e o fazerse "conhecido" no círculo da imprensa (de uma cidade, estado, região) pretendida para atuação representam credenciais valiosas para a entrada dos chargistas na imprensa. E isso fica ainda mais claro quando nos debruçamos sobre os dados já discutidos aqui: através deles podemos ver que os pro- dutores de charges para impressos são, em sua maioria, desenhistas em cujo histórico profissional figuram outras inserções no espaço da mídia anteriores ao chargismo.

Por fim, o chargismo jornalístico é uma forma de atuação que se realiza na imprensa e, nesse sentido, algumas características da atividade jornalística também se estendem ao chargismo como, por exemplo, o papel das redes de relações como integrante das credenciais de inserção no espaço de atuação jornalístico. Conforme demonstrado por autores como Rieffel (1984) e Petrarca (2007), o conjunto dos vínculos e/ou redes sociais tecidos pelos jornalistas atuam, entre outras frentes, no sentido do reconhecimento e do posicionamento desses profissionais na imprensa. Consonante a isso, vimos aqui como as vinculações dos chargistas com integrantes do jornalismo local funcionaram como "pontes" muito eficazes entre eles e gestores de empreendimentos midiáticos diferentes, pois uma vez acionadas essas vinculações, elas criaram oportunidades de trabalho para os desenhistas de charges quase inacessíveis por outros expedientes. Nesse sentido, o que esse trabalho vem a demonstrar é que atuando dentro do universo jornalístico os chargistas também têm nas suas redes de relações um recurso profissional importante.

Enfım, nosso foco de atenção aqui foi demonstrar o papel desempenhado por recursos advindos das instâncias jornalística e artística, juntamente com as redes de relações tecidas em espaços diversos, como credenciais para o chargismo jornalístico. Desenhar charges e as veicular em suportes diversos (panfletos, livros, sítios da Internet) é prática relativamente comum para muitos desenhistas, porém fazê-lo na imprensa é algo bem menos comum e a posse dos recursos citados é que representa o principal dife- 
rencial dos produtores de charges que atuam nos jornais. Enfim, o que ficou demonstrado é que o sucesso de uma empreitada como produtor de charges para jornais é intimamente dependente da aquisição de um conjunto variado de qualificativos sociais e do jogo realizado com estes recursos.

\section{Referências}

AZEVEDO, S. S.; CHOU, J. W. T.; SANTOS, E. (Orgs.). Dois séculos de artes visuais em Sergipe: Dicionário de artes visuais. Sergipe - Secretaria de Estado da Cultura. Aracaju-SE: Sociedade Semear, 2008.

BECKER, H. Outsiders: estudo de sociologia do desvio. Rio de Janeiro: ZAHAR, 2008.

BOIGEOL, A.; DEZALAY, I. De l'agent d'affaires au barreau: conseils jurudiques et la construction d'un espace professionnel. Genèses, no 27, p. 4968, juin. 1997.

BOLTANSKI, L. Les Cadres. La formation d'un groupe social. Paris: Minuit, 1982.

BONELLI, M. G. 0 Instituto da Ordem dos Advogados Brasileiros e o Estado: a profissionalização no Brasil e os limites dos modelos centrados no mercado. In: Revista Brasileira de Ciências Sociais, vol. 14, no 39, p. 61-81, fevereiro de 1999.

BOURDIEU, P. Homo Academicus. Paris: Minuit, 1984.

BOURDIEU, P. La noblesse d'État: grandes écoles et esprit de corps. Paris: Minuit, 1989.

BOURDIEU, P. O Poder Simbólico. Tradução de Fernando Tomaz (português de Portugal). 11 ed. Rio de Janeiro: Bertrand Brasil, 2007, cap. II e VI.

CORADINI, O. L. Grandes famílias e elite 'profissional' na medicina no Brasil. In: História, Ciência e Saúde - Manguinhos, v.3, no 3, p. 425-466. Rio de Janeiro, novembro de 1996.
CORADINI, O. L. Em nome de quem? Recursos sociais no recrutamento de elites políticas. Rio de Janeiro: Relume Dumará, 2001.

KUCINSKI, B. Jornalistas e revolucionários: nos tempos da imprensa alternativa. São Paulo: EDUSP, 2003.

MELO, J. M. Jornalismo opinativo: gêneros opinativos no jornalismo brasileiro. 3 ed. Campos de Jordão-SP: Mantiqueira, 2003.

MERCKLÉ, P. La sociologie des réseaux sociaux. Paris: La Découvert \& Syros, 2004.

PETRARCA, F. R. O Jornalismo como profissão": recursos sociais, titulação acadêmica e inserção profissional dos jornalistas no Rio Grande do Sul. Tese de Doutorado em Sociologia. Porto Alegre: UFRGS, 2007.

RIEFFEL, R. L'élite des Journalistes. Paris: Presses Universitaires de France, 1984.

SODRÉ, N. W. História da Imprensa no Brasil. 4 ed. Rio de Janeiro: Mauad, 1999.

Eletrônicas:

$<$ http://www.lagartense.com.br>. Acesso em 22 mar. 2013.

$<$ http://www.lagartense.com.br>. Acesso em 03 mar. 2013.

$<$ http://www.educar-se.com/v3/index.php/personalidades>. Acesso em 23 mar. 2013. 
RESUMO

Este artigo analisa as condições sociais de entrada e de atuação dos chargistas no jornalismo impresso. 0 material que serviu de base para a construção do artigo consistiu de uma pesquisa desenvolvida sobre um conjunto de chargistas que desenham ou já desenharam para jornais em Sergipe. A pesquisa evidenciou que as inserções prévias no universo jornalístico e as atuações na produção de desenhos artísticos constituem ingredientes fundamentais para o ingresso e a permanência dos produtores de charges na nos jornais.

\section{PALAVRAS-CHAVES}

Recursos Sociais. Atuação Profissional. Jornalismo. Chargistas.

\section{ABSTRACT}

This article analyzes the social conditions for ingress and continuity of cartoonists in print journalism. The material used to the construction of the article consisted of a developed research about cartoonists who work for newspapers in Sergipe. The research showed that the previous inserts in the journalistic universe and the professional practice in the production of artistic designs are very important for ingress and continuity of cartoons producers in the newspapers.

\section{KEYWORDS}

Social resources. Professional Practice. Journalism. Cartoonists. 